\title{
Hard epoxy thermosets obtained via two sequential epoxy-amine condensations
}

\author{
Osman Konuray a , Aina García a , José M. Morancho ${ }^{\text {a }}$, Xavier Fernández-Francos a Àngels Serra ${ }^{\text {b }}$, \\ Francesc Ferrando ${ }^{c}$, Montserrat García-Alvarez ${ }^{\mathrm{d}}$, Xavier Ramis ${ }^{\mathrm{a}, *}$ \\ a Thermodynamics Laboratory, ETSEIB Universitat Politècnica de Catalunya, Av. Diagonal 647, 08028 Barcelona, Spain \\ ${ }^{\mathrm{b}}$ Department of Analytical and Organic Chemistry, Universitat Rovira i Virgili, C/ Marcel-lí Domingo s/n, Edifici N4, 43007 Tarragona, Spain \\ ${ }^{c}$ Department of Mechanical Engineering, Universitat Rovira i Virgili, C/Av. Països Catalans, 26, 43007 Tarragona, Spain \\ d Department of Chemical Engineering, ETSEIB Universitat Politècnica de Catalunya, Av. Diagonal 647, 08028 Barcelona, Spain
}

\section{A R T I C L E INFO}

\section{Keywords:}

Epoxy

Diamine

Dual-curing

Thermosets

Shape memory

\begin{abstract}
A B S T R A C T
A new family of dual-curable poly( $\beta$-hydroxyamine ether) thermosets based on amine-epoxy formulations has been prepared and characterized. Both curing stages consist in an epoxy-amine polycondensation, each having different reactivity. Whereas the first one is carried out at relatively low temperature using an aliphatic flexible amine, the second is carried out at high temperature with a rigid aromatic amine. The sequentiality of the curing and the stability of the intermediate materials can be established in the basis of the different nucleophilicity of the amines used. The aromatic amine, with a weakly nucleophilic character, is not able to react with epoxides during the first stage at low temperature. The intermediate and final materials exhibit a wide range of properties, thanks to the different glass transition of both epoxy-amine networks, and can be tuned by changing the relative proportion of both diamines in the formulation. The participation of the epoxy resin in both curing stages ensures the homogeneity of the prepared materials, rendering them excellent candidates for applications such as adhesives or smart materials.
\end{abstract}

\section{Introduction}

Dual-curing strategy is used in many applications since it provides great flexibility in product design and control of the curing, especially when both curing stages take place sequentially [1-4]. In this case, partially-cured intermediate materials after the first curing stage can be safely stored, or sent for further processing and assembly.

However, sequentiality in dual-curing is difficult to achieve and could present some problems and disadvantages. Among the different strategies used, many papers investigate the use of off-stoichiometric formulations [5-12]. In these systems, the first stage is a self-limiting step-growth reaction and the second one a chain-growth polymerization of the excess of one monomer, thermally or photochemically triggered. Depending on the mechanism of the second stage, a latent initiator is necessary to ensure the sequentiality of the curing and the storage stability of the intermediate materials. These initiators are usually added in elevated amounts since the released active species constitutes only a small part of the molecule [10,11]. In this way, fragments of the initiator remain in the final material, in addition to increasing material costs. Acrylates and methacrylates are two of the most common monomers used in excess in this strategy [5-9]. Their UV-induced homopolymerization during second stage presents some significant drawbacks: (a)

\footnotetext{
* Corresponding author.

Email address: ramis@mmt.upc.edu (X. Ramis)
} 
(a)

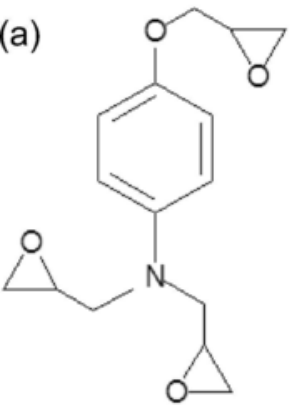

(b)<smiles>CC(N)COCC(C)N</smiles><smiles>Nc1ccc(S(=O)(=O)c2ccc(N)cc2)cc1</smiles>

Scheme 1. Molecular structures of the chemicals used: (a) TGAP, (b) JEF with $n=6$ and (c) DDS.

Table 1

Notation and composition of the formulations studied in this work.

\begin{tabular}{|c|c|c|c|c|}
\hline Formulation & $(\text { eq. } \mathrm{NH} / \mathrm{ee})_{1}^{\mathrm{a}}$ & $(\text { eq. } \mathrm{NH} / \mathrm{ee})_{2}{ }^{\mathrm{b}}$ & $W_{1 \text { stage }} / W_{\text {tot }}{ }^{\mathrm{c}}(\%)$ & $W_{2 \text { stage }} / W_{\text {tot }}{ }^{\mathrm{c}}(\%)$ \\
\hline TGAPJEF11 & 1 & - & 100 & - \\
\hline TGAPJEFDDS1_0.75_0.25 & 0.75 & 0.25 & 79 & 21 \\
\hline TGAPJEFDDS1_0.5_0.5 & 0.50 & 0.5 & 55.4 & 44.6 \\
\hline TGAPJEFDDS1_0.25_0.75 & 0.25 & 0.75 & 29.3 & 70.7 \\
\hline TGAPJEFDDS1_0.1_0.9 & 0.10 & 0.9 & 12 & 88 \\
\hline TGAPDDS11 & - & 1 & - & 100 \\
\hline
\end{tabular}

a Equivalents of reactive amine hydrogens of JEF (Stage 1)/equivalents of epoxy groups.

b Equivalents of reactive amine hydrogens of DDS (Stage 2)/equivalents of epoxy groups.

c Weight fractions (\%) of stage 1 and stage 2 .

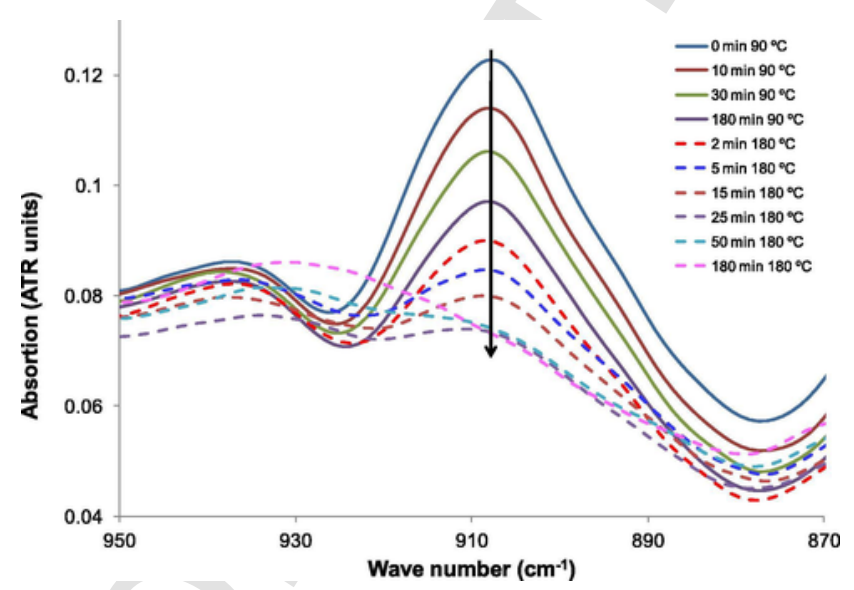

Fig. 1. Evolution of FTIR spectra at $90^{\circ} \mathrm{C}$ (solid line) and at $180^{\circ} \mathrm{C}$ after $180 \mathrm{~min} 90^{\circ} \mathrm{C}$ (dashed line) for DGJEF DGJEFDDS1_0.5_0.5.

the intrinsic oxygen inhibition of free-radical polymerizations, (b) the insufficient cure in shadowed areas and (c) some undesired features of the networks obtained via chain-growth polymerization such as high shrinkage, low homogeneity and low capacity for mechanical energy absorption.

The formation of dual networks based on two consecutive click reactions is another widely used strategy. Most of these systems include thiol in their formulation: (a) photoinitiated thiol-ene followed by thermal thiol-epoxy reaction [13], (b) combination of base catalyzed thiol-acrylate Michael addition and radical thiol-ene [14], (c) sequential thiol-isocyanate and thiol-Michael addition on acrylates in the presence of initiators with different nucleophilicities [5], (d) thiol/acrylate and thiol/epoxy triggered by a photobase generator [15] and (e) thermal or UV-induced consecutive isocyanate-thiol and epoxy-thiol reactions [16,17]. The control of sequentiality is not an easy task. In some cases, the curing is accompanied by secondary reactions such as epoxy or acrylate homopolymerization. The presence of a latent base is necessary in some of these formulations as well. The flexible structure of the commercially available thiols and the formation of flexible thioether linkages, lead to networks with relatively low glass transition temperatures and poor mechanical characteristics, thus limiting their use as structural materials (). 

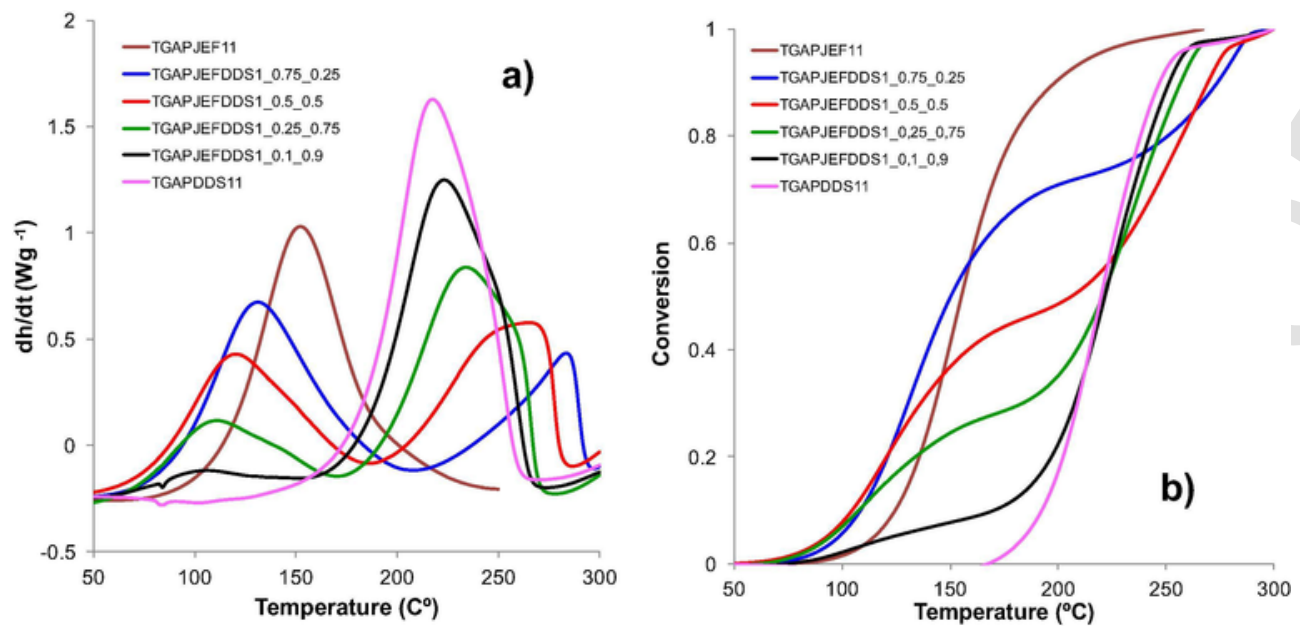

Fig. 2. DSC thermograms corresponding to the dynamic curing at $10^{\circ} \mathrm{C} / \mathrm{min}$ of (a) and epoxy conversions versus temperature (b) for all the systems studied.

Table 2

$T_{g}$ and $\Delta C_{p}$ before and after each curing stage in the oven ( $o$, int and $\infty$ indicate before stage 1. after stage 1 and after stage 2, respectively). Relationship between the segmental mobilities of the crosslinked and noncrosslinked polymers, calculated as $\lambda=\Delta C_{p \infty} / \Delta C_{p o .}$. Total reaction heat $\Delta h_{\text {tot }}$ (obtained dynamically), residual reaction heat after Stage $1 \Delta h_{1 . r e s}$ (obtained dynamically after $180 \mathrm{~min}$ at $90^{\circ} \mathrm{C}$ ).

\begin{tabular}{llllllllll}
\hline Formulation & $T_{g o}\left({ }^{\circ} \mathrm{C}\right)$ & $\Delta C_{p o}(\mathrm{~J} / \mathrm{gKK})$ & $T_{\text {gint }}\left({ }^{\circ} \mathrm{C}\right)$ & $\Delta C_{\text {pint }}(\mathrm{J} / \mathrm{g} \mathrm{K})$ & $T_{g \infty}\left({ }^{\circ} \mathrm{C}\right)$ & $\Delta C_{p \infty}(\mathrm{J} / \mathrm{gK})$ & $\lambda$ & $\Delta h_{1 . r e s}(\mathrm{~kJ} / \mathrm{ee})$ & $\Delta h_{\text {tot }}(\mathrm{kJ} / \mathrm{ee})$ \\
\hline TGAPJEF11 & -70 & 0.713 & 63 & & 63 & 0.403 & 0.56 & \\
TGAPJEFDDS1_0.75_0.25 & -48 & 0.674 & 36 & 0.505 & 84 & 0.342 & 0.50 & 27 \\
TGAPJEFDDS1_0.5_0.5 & -35 & 0.652 & 27 & 0.482 & 119 & 0.222 & 0.34 & 49 & 102 \\
TGAPJEFDDS1_0.25_0.75 & -23 & 0.635 & 12 & 0.555 & 184 & 0.161 & 0.25 & 75 & 102 \\
TGAPJEFDDS1_0.1_0.9 & -18 & 0.537 & -5 & 0.461 & 195 & 0.124 & 0.23 & 89 & 93 \\
TGAPDDS11 & -16 & 0.467 & & & 235 & 0.100 & 0.21 & 97 \\
\hline
\end{tabular}

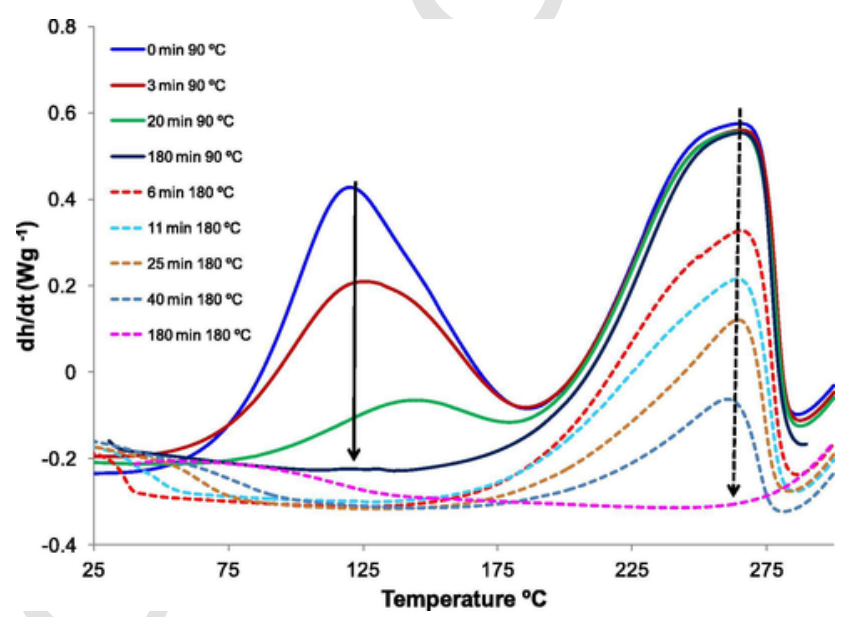

Fig. 3. Evolution of the postcuring at $10^{\circ} \mathrm{C} / \mathrm{min}$ of TGAPJEFDDS1_0.5_0.5 samples during isothermal dual curing. DSCs of initial mixtures after curing at $90^{\circ} \mathrm{C}$ for different durations (solid curves). DSCs of intermediate materials after curing at $180^{\circ} \mathrm{C}$ for different times (dashed curves).

Epoxy resins are one of the most important thermosetting resins for many engineering applications, such as in electrical insulation $[18,19]$ thanks to their superior mechanical properties and thermal/chemical stability, coupled with low curing induced shrinkage.

For applications requiring tough materials, the intrinsic brittleness associated with highly crosslinked structures of epoxies still remains a major drawback. Extensive research for toughening epoxy thermosets are generally focused on the incorporation of a second component within the epoxy matrix, with a significant decrease of the glass transition. The preparation of epoxy thermosets with enhanced toughness and high glass transition temperature is a problem yet to be solved [20-22]. 


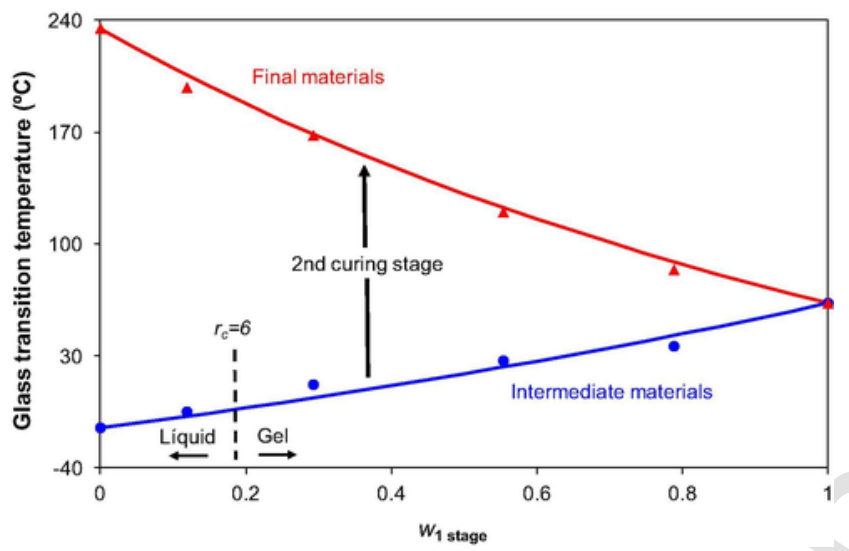

Fig. 4. Intermediate (circles) and final (triangles) experimental glass transition temperatures ( $T_{g}$ ) and Fox Equation fits (solid line) against weight fraction of Stage 1 network. The theoretical minimum Stage $1 \mathrm{wt}$ fraction $W_{1 \text { stage }}=0.19$ (critical ratio of $r_{c}=6$ ) for gelation takes place during stage 1 (shown as a dashed line).

Table 3

Experimental gelation data $\left(\alpha_{\text {gel }}^{\exp }\right.$ and $\left.t_{g e l}\right)$ obtained by isothermal DSC/TMA combined assays. $\alpha_{g e l}^{\text {theor }}$ obtained by using Flory-Stockmayer equation.

\begin{tabular}{llll}
\hline Formulation & $r^{\mathrm{a}}$ & $\alpha_{\text {gel }}^{\text {theor }}$ & $\alpha_{\text {gel }}^{\text {exp }}$ \\
\hline Stage $1\left(90^{\circ} \mathrm{C}\right)$ & & & \\
TGAPJEF11 & 1 & 0.408 & 0.622 \\
TGAPJEFDDS_0.75_0.25 & 1.33 & 0.353 & 0.464 \\
TGAPJEFDDS_0.5_0.5 & 2 & 0.289 & 0.402 \\
TGAPJEFDDS_0.25_0.75 & 4 & 0.204 & 0.246 \\
TGAPJEFDDS_0.1_0.9 & 10 & 0.129 & Not gel \\
Stage 2 $\left(180^{\circ} \mathrm{C}\right)$ & & 51.8 \\
TGAPJEFDDS_0.1_0.9 & & Not gel & \\
TGAPDDS11 & 1.1 & 0.348 & 0.48 \\
\hline
\end{tabular}

a Ratio between epoxy groups and reactive amine hydrogens.

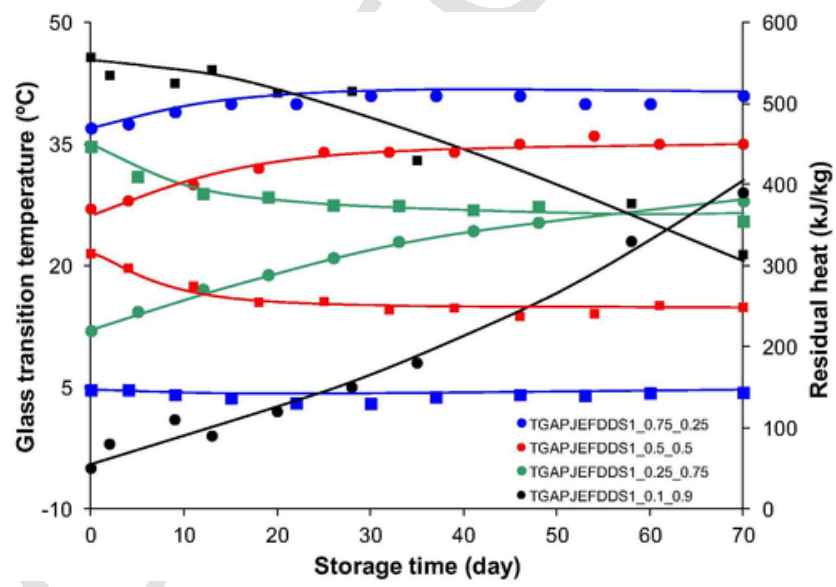

Fig. 5. Intermediate glass transition temperatures (circles) and residual heat (squares) against storage time.

Taking all of this into account, herein we report the preparation and characterization of a new family of thermosets based on commercial amine-epoxy formulations, with two amines of different reactivity and rigidity. The first stage of curing (stage 1) was an epoxy-aliphatic amine polycondensation at a relatively low temperature and the second stage (stage 2) was an epoxy-aromatic amine polycondensation at a higher temperature. The objective of this work was four-fold: (a) to develop a new dual-curing concept based on the combination of two thermal curing autocatalyzed processes at different temperatures, (b) to obtain a new family of thermosets for flexible processing and tailoring of intermediate and final materials (c) to enhance toughness of highly crosslinked epoxy-amine thermosets and (d) to explore some applications of the intermediate and final materials as adhesives and conformable materials and shape memory materials, respectively 


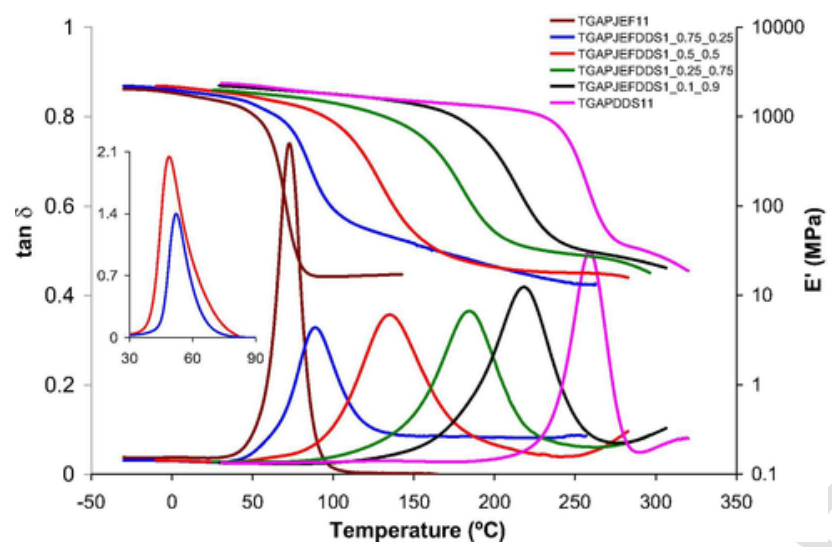

Fig. 6. Storage moduli and $\tan \delta$ curves as function of temperature of fully cured epoxy-amine formulations. Inset shows tan $\delta$ - $T$ curves of intermediate materials that gelled during stage 1 . The same legend applies to the inset.
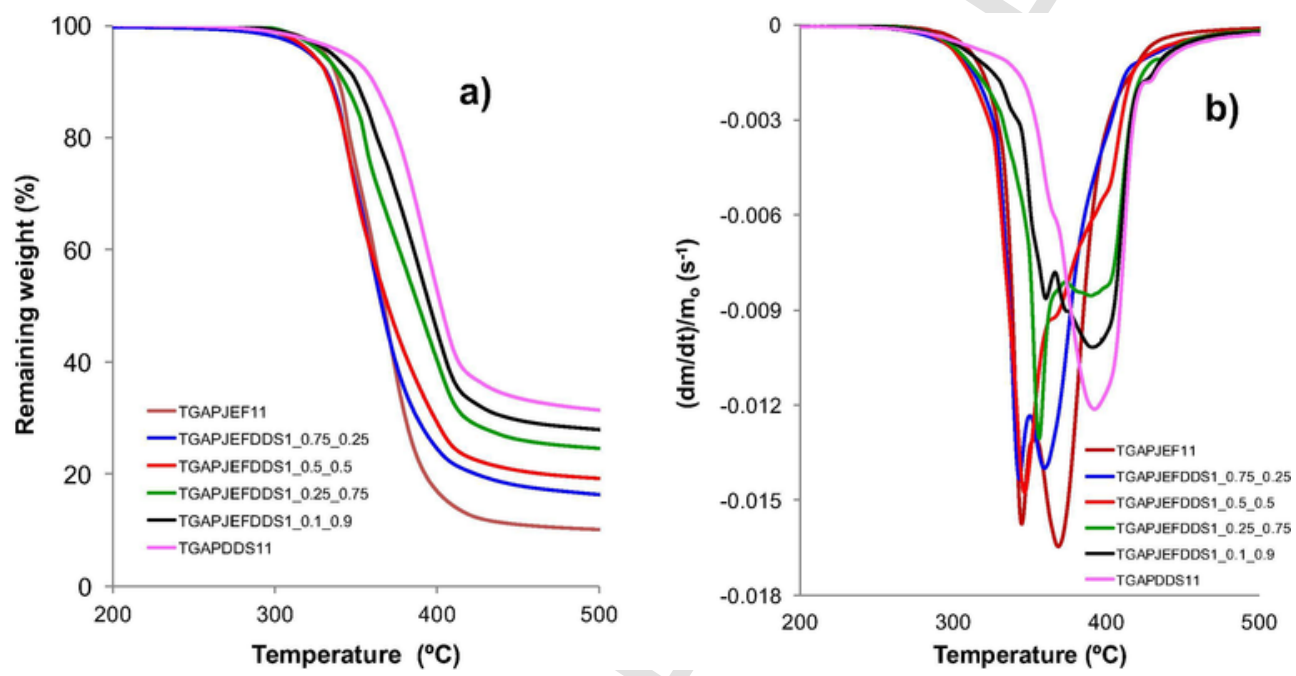

Fig. 7. Remaining weight curves (a) and rate of weight loss (b) against temperature at $10^{\circ} \mathrm{C} / \mathrm{min}$ in nitrogen atmosphere of fully cured formulations.
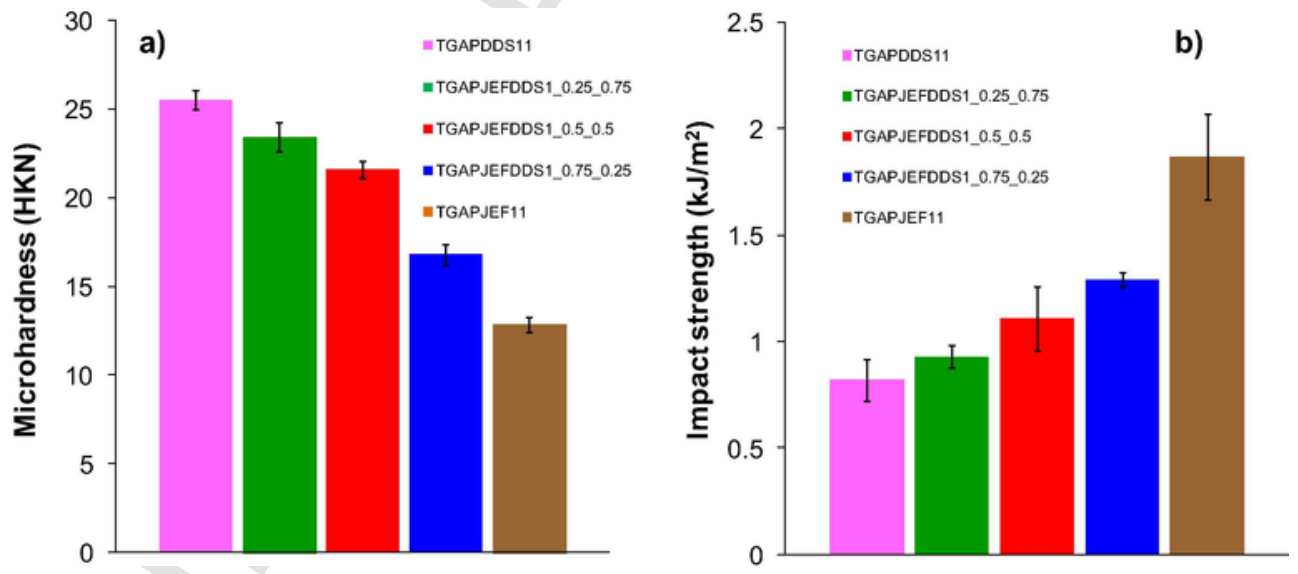

Fig. 8. Microhardness (a) and impact strength (b) for some of the thermosets obtained.

The kinetics of both curing stages, the monomer conversion and the storage stability after the first stage were studied by calorimetry and FTIR spectroscopy. Gelation during curing was determined by thermomechanical analysis. The thermal and mechanical properties of the intermediate and final materials were also measured. All materials were highly stable after the first stage and 


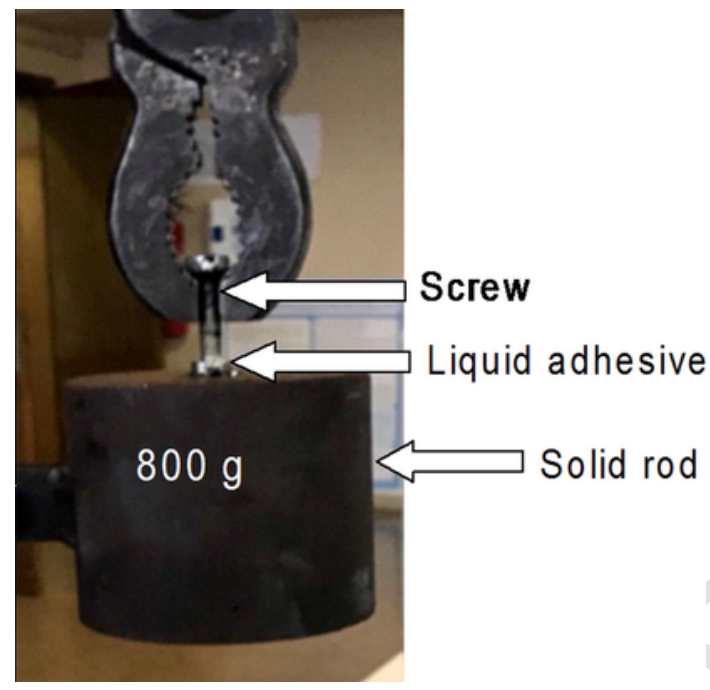

Fig. 9. Illustration of the adhesive bonding test for TGAPJEFDDS_0.1_0.9 formulation.
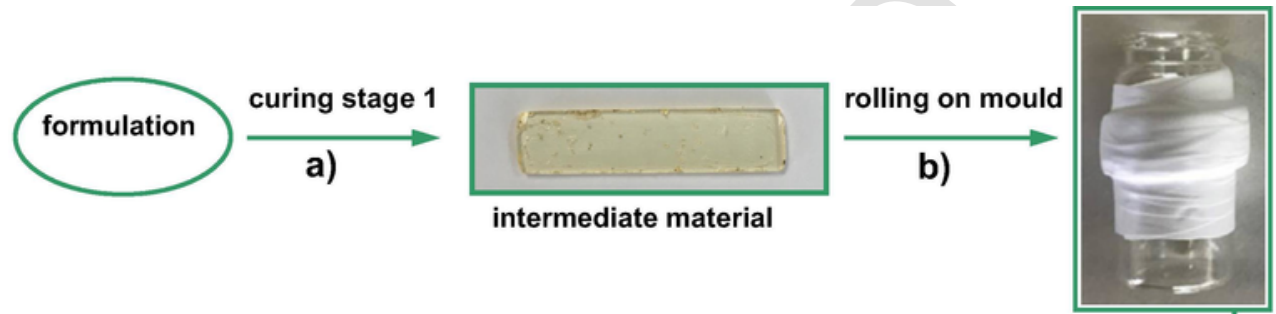

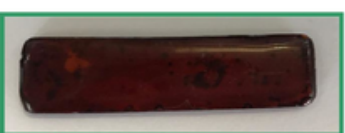

termporary shape

recovery of permanent shape

e)

\section{imposition of temporary shape}

d)

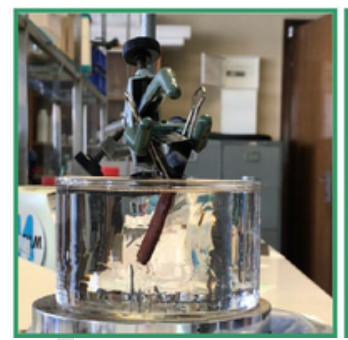

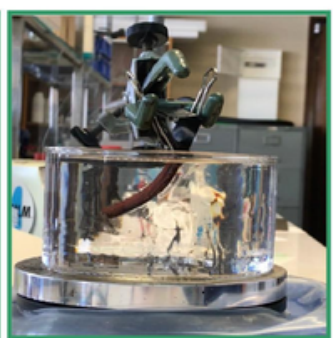

curing stage 2 and peeled off

c)

permanent shape

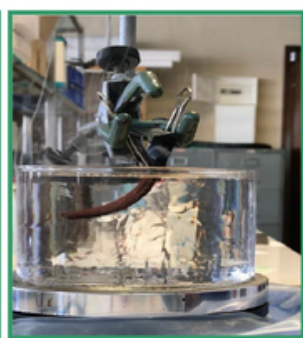

Fig. 10. Representation of the bent-shaped sample processing, shape memory programming and recovery process.

they exhibited a wide array of properties depending on the relative contribution of each curing stage. The adhesive capability of the non-gelled intermediate materials and the shape memory potential of the final materials have been demonstrated.

\section{Experimental methods}

\subsection{Materials}

The tri-glycidyl p-aminophenol epoxy resin (TGAP hereafter) with trade name Araldite MY0510 (Huntsman Advanced Materials) and an epoxy equivalent $95 \mathrm{~g} /$ ee determined by hydrobromic acid titration following standard procedures [23], was used after dried 
in vacuum. As hardener, 4,4-diamino diphenyl sulphone (DDS hereafter) and poly(propylene glycol) bis(2-aminopropyl ether) (Jeffamine, $M_{w}=400 \mathrm{~g} / \mathrm{mol}$ ) (JEF hereafter), both supplied by Sigma-Aldrich were used as received (see Scheme 1).

\subsection{Sample preparation}

Samples were prepared in $5 \mathrm{~mL}$ vials in 1-2 gr batches using the following procedure: DDS was weighed and added to TGAP and was kept under magnetic stirring agitation at $90^{\circ} \mathrm{C}$ for $5-10 \mathrm{~min}$ until the solution became clear. The mixture was left to cool down to room temperature after which the required amount of JEF was added, quickly stirred and immediately sent to analysis or sample preparation. Neat TGAP-JEF formulation was prepared mixing both components directly at room temperature. Although an excess of epoxy is recommended by some manufacturers, it was decided to use a ratio of 1:1 for epoxy to amine hydrogen, since these stoichiometric formulations showed slightly higher glass transition temperatures and heats of reaction in our preliminary tests.

We coded our epoxy-mixtures as TGAPJEFDDS1_x_y, where $\mathrm{x}$ and $\mathrm{y}$ indicate the fraction of epoxy groups that reacts during stage 1 and stage 2, respectively. As an example, TGAPJEFDDS1_0.75_0.25 is a formulation in which three parts of epoxy equivalents react with amine hydrogens coming from JEF and the other part with amine hydrogens coming from DDS (this formulation contains 100 epoxy, $75 \mathrm{JEF}$, and 25 DDS equivalents). It should be commented that TGAP has three equivalents of epoxide per mol and the two diamines possess four equivalents of NH per mol. Stoichiometric neat formulations were coded as TGAPJEF11 and TGAPDDS11. Table 1 shows the composition of all the formulations.

Intermediate and fully cured samples for dynamic mechanical analysis and thermal analysis assays were prepared in a mould with dimensions ca. $1 \times 13 \times 50 \mathrm{~mm}^{3}$. For impact tests, samples of $3 \times 13 \times 25 \mathrm{~mm}^{3}$ were used. Liquid formulations were poured into the mould and kept in an oven at $90^{\circ} \mathrm{C}$ for $180 \mathrm{~min}$ to carry out the first curing stage (TGAP-JEF condensation). Some of these samples were subsequently cured at $180^{\circ} \mathrm{C}$ for $180 \mathrm{~min}$ to carry out the second curing stage (TGAP-DDS condensation) and then postcured at $250^{\circ} \mathrm{C}$ for $30 \mathrm{~min}$. This postcuring was performed to all samples, although it was strictly necessary only for DDS-rich formulations that vitrified at $180^{\circ} \mathrm{C}$. The curing schedule was selected after inspection of dynamic curing thermograms and by means of simulations using isoconversional data, by the methodology explained in previous works (results not shown) [24]. By means of a dynamic postcuring in a DSC and FTIR, it was verified that the curing was complete at the end of both curing stages. Intermediate formulations showed residual heats proportional to the epoxy part that reacted during stage 2 and final materials did not produce any residual heat.

\subsection{Fourier infrared spectroscopy (FTIR)}

A Bruker Vertex FTIR spectrometer equipped with an attenuated-total-reflectance accessory with a diamond crystal (Golden Gate heated single-reflection diamond ATR) was used to monitor the curing process. Spectra were acquired in the mid-infrared region (spectral range of $600-4000 \mathrm{~cm}^{-1}$ ) with a resolution of $4 \mathrm{~cm}^{-1}$ averaging 20 scans for each spectrum. The evolutions of the functional groups were monitored during isothermal curing at $90^{\circ} \mathrm{C}$ (stage 1 ) and $180^{\circ} \mathrm{C}$ (stage 2), taking the band at $1508 \mathrm{~cm}^{-1}$, attributed to the aromatic rings, as a reference. The conversion of epoxides was determined by the Lambert-Beer law from the normalized change of absorbance at $910 \mathrm{~cm}^{-1}$ (epoxy bending). All formulations were observed to achieve complete curing at the end of the two stages of curing.

As an example, Fig. 1 shows some spectra collected during reaction at $90^{\circ} \mathrm{C}$ (stage 1 ) and at $180^{\circ} \mathrm{C}$ after $180 \mathrm{~min}$ at $90^{\circ} \mathrm{C}($ stage 2 ) of formulation DGJEFDDS1_0.5_0.5. It can be observed the complete disappearance of the epoxy band at $910 \mathrm{~cm}^{-1}$.

The high temperature of stage 2 raises a concern for the possibility of epoxy homopolymerization. In fact, at this stage, the primary amine bands at wavenumbers 1625,3375 , and $3480 \mathrm{~cm}^{-1}$ were observed to disappear completely (data not shown). As expected, the peak associated to secondary amines at $3400 \mathrm{~cm}^{-1}$ increased simultaneously with the decrease of primary amines. However as the curing progressed, the peak at $3400 \mathrm{~cm}^{-1}$ decreased, but due to the overlapping of hydroxyl absorption band (between 3200 and $3600 \mathrm{~cm}^{-1}$ ), exact quantification was not possible. Nevertheless, since a DSC scan revealed the neat TGAP does not begin to homopolymerize below $200^{\circ} \mathrm{C}$ (results not shown), it can be safely assumed that stage 2 is primarily epoxy-amine condensation.

\subsection{Gelation}

A Mettler thermo-mechanical analyzer SDTA840 was used to determine the gel point. A silanized glass fiber disc about $5 \mathrm{~mm}$ in diameter was impregnated with the liquid (uncured) formulation and sandwiched between two aluminium discs. The sample was placed at $90^{\circ} \mathrm{C}$ for $180 \mathrm{~min}$ and subjected to an oscillatory force from 0.005 to $0.1 \mathrm{~N}$ with an oscillation frequency of $0.083 \mathrm{~Hz}$. The gel time, $t_{\text {gel }}$, was taken as the onset in the decrease of the oscillation amplitude measured by the probe. The conversion of epoxy groups at the gel point, $\alpha_{\text {gel }}$, was determined as the conversion reached in the DSC at the gel time. Gel point of samples that do not gelled during stage 1 , was determined in the same way but at $180^{\circ} \mathrm{C}$ for $180 \mathrm{~min}$ (stage 2) after the first stage was finished.

The theoretical conversion of epoxy groups at the gel point, $\alpha_{\text {gel }}$, during epoxy-amine condensation (stage 1 ) was calculated assuming ideal random step-wise reaction, using the well-known Flory-Stockmayer equation [25,26]:

$\alpha_{g e l}^{\text {theor }}=\frac{1}{\sqrt{\mathrm{r}(\mathrm{f}-1)(\mathrm{g}-1)}}$ 
where $r$ is the epoxy/hydrogen amine equivalent ratio, $f=3$ the epoxy monomer functionality and $g=4$ the amine functionality. $\alpha_{g e l}^{\text {theor }}$ of samples that gel during stage 2, TGAPJEFDDS1_0.1_0.9 and TGAPDDS11, was estimated taking into account the distribution of reactive species and polymer distribution at the end of stage 1, following a similar procedure to the approaches for multi-stage processes described in the literature $[27,28]$ and the activation of pre-existing branching points proposed by Dušek and Dušková-Smrčková [29]. Non-idealities such as substitution effects or intra-molecular cyclization were not considered in the calculations, as a first approximation.

\subsection{Differential scanning calorimetry (DSC)}

Calorimetric analyses of materials were carried out on a Mettler DSC822e thermal analyzer calibrated using an indium standard (heat flow calibration) and used to monitor reactions heats and residual reaction heats or to determine glass transition temperatures $\left(T_{g}\right)$. Samples of $10 \mathrm{mg}( \pm 0.1 \mathrm{mg})$ were placed in aluminium pans and were scanned under $\mathrm{N}_{2}$ atmosphere in the analyzer using various temperature programs depending on the type of measurement. Dynamic curings, postcurings and $T_{g}$ determinations were performed by choosing a temperature ramp of $10^{\circ} \mathrm{C} / \mathrm{min}$. Isothermal curing for gel time determination were performed at $90^{\circ} \mathrm{C}$ for $180 \mathrm{~min}$ (stage 1 ) and at $180^{\circ} \mathrm{C}$ for $180 \mathrm{~min}$ (stage 2 ).

Non isothermal degree of conversion was determined as the quotient between the reaction heat released up to a temperature and the total reaction heat released during the dynamic experiment. For isothermal storage stability experiments, conversion was calculated as the quotient between the reaction heat released up to a time, determined as difference between the total dynamic heat and the residual heat, and the total dynamic heat.

The $T_{g}$ of the uncured, intermediate (after $180 \mathrm{~min}$ at $90^{\circ} \mathrm{C}$ in oven) and final (after $180 \mathrm{~min}$ at $180^{\circ} \mathrm{C}$ plus $30 \mathrm{~min}$ at $250^{\circ} \mathrm{C}$ in oven) materials were determined from a scan at $10^{\circ} \mathrm{Cmin}^{-1}$, and taken as the half-way point in the jump in the heat capacity step, following the DIN 51007 method in the STARe software by Mettler and the error was estimated was $\pm 1^{\circ} \mathrm{C}$. The jump in the heat capacity, $\Delta C_{p}$ of uncured, intermediate and final materials were also measured.

To compare with experimental results $T_{g}$ 's were calculated using the copolymer rule given by Fox equation [30], the weight compositions and the experimental $T_{g}$ of TGAP-JEF and TGAP-DDS networks in their cured or uncured states, depending on the curing stage analyzed.

\subsection{Dynamic mechanical analysis (DMA)}

Fully-cured and gelled intermediate materials were analyzed using a TA Instruments DMA Q800 device. Prismatic rectangular samples (about $1 \times 13 \times 20 \mathrm{~mm}^{3}$ ) were analyzed by DMA using a single cantilever clamp at a frequency of $1 \mathrm{~Hz}$ and $0.05 \%$ strain at $3{ }^{\circ} \mathrm{C} / \mathrm{min}$ from $-50{ }^{\circ} \mathrm{C}$ up to a temperature sufficiently high for complete network relaxation. The peak temperatures of tan $\delta$ curves were taken as $\alpha$-relaxation temperatures, related with the glass transition temperatures.

\subsection{Thermogravimetric analysis (TGA)}

Thermogravimetric analysis was carried out with a Mettler TGA/SDTA 851e/LF/1100 thermobalance. Samples, obtained by dual curing, with an approximate mass of $10 \mathrm{mg}$ were degraded between 30 and $800^{\circ} \mathrm{C}$ at a heating rate of $10^{\circ} \mathrm{C} / \mathrm{min}$ in $\mathrm{N}_{2}$ atmosphere $\left(50 \mathrm{~cm}^{3} / \mathrm{min}\right.$ measured in normal conditions).

\subsection{Storage stability}

Isothermal storage stability experiments were performed for all dual formulations. After stage $1\left(180 \mathrm{~min}\right.$ at $\left.90^{\circ} \mathrm{C}\right)$, samples were stored in a thermostatic oil bath at controlled temperatures of $30^{\circ} \mathrm{C} . T_{g}$ 's and residual heats of intermediate materials at different times of storage were measured by DSC, as explained in Section 2.5. Intermediate materials are reactively stable as long as they maintain their $T_{g}$, and their residual heats stay equal to the reaction heat of stage 2 .

\subsection{Microhardness}

Microindentation Knoop hardness was measured with a Wilson Wolpert 401 MAV device following ASTM D1474-13. For each material, a minimum of 20 determinations were made with a confidence level of $95 \%$. The Knoop microindentation hardness (KHN) was calculated from the following equation:

$H K N=\frac{\mathrm{L}}{A_{P}}=\frac{\mathrm{L}}{1^{2} C_{P}}$

where $L$ is the load applied to the indenter $(0.025 \mathrm{~kg}), A_{P}$ is the projected area of indentation in $\mathrm{mm}^{2}, C_{P}$ is the indenter constant $\left(7.028 \times 10^{2}\right)$ relating $l^{2}$ to $A_{P}$. 


\subsection{Impact resistance}

Impact test was performed at room temperature by means of a Zwick 5110 impact tester according to ASTM D 4508-10 using rectangular samples. The pendulum employed had a kinetic energy of $1 \mathrm{~J}$. For each material, a minimum of 10 determinations were made with a confidence level of $95 \%$. The impact strength (IS) was calculated from the energy absorbed by the sample upon fracture as:

$$
I S=\frac{\mathrm{E}-\mathrm{E}_{0}}{\mathrm{~S}}
$$

where $E$ and $E_{0}$ are the energy loss of the pendulum with and without sample respectively, and $S$ is the cross-section of the samples.

\section{Results and discussion}

\subsection{Dual curing behaviour}

Although previously reported data on the curing of epoxides using JEF and DDS as curing agent [10,31] suggest that the dual-curing of a ternary TGAP-JEF-DDS formulation could be sequential, there are no published works on TGAP-JEF systems. So, first of all, we investigated the possibility to use these ternary formulations as precursors of thermosets obtained via dual sequential curing. Fig. $2 \mathrm{a}$ and $\mathrm{b}$ show the DSC traces and conversions versus temperature of different formulations cured dynamically al $10{ }^{\circ} \mathrm{C} / \mathrm{min}$. The dual nature of curing can be observed, with two clearly separated processes. By comparison with the neat formulations, these can be attributed to the TGAP-JEF condensation at low temperature and to the TGAP-DDS condensation at high temperature, respectively. The large difference between the curing temperatures of the systems containing JEF and DDS can be attributed to the different nucleophilic character of the two amines. The low reactivity of DDS is due to the fact that the nitrogen lone pairs are delocalized by resonance over the aromatic rings. The sequentiality of the curing process is also evident from the conversions achieved at the two curing stages (see Fig. 2b) which practically agree with the composition of the mixture. Besides, there is no significant overlapping of the two stages.

The total reaction heats of all the systems studied (see Table 2) are in agreement with the literature which reports that most epoxy/ amine values are close to $100 \mathrm{~kJ} / \mathrm{ee}[10,32]$. This indicates that epoxides reacted almost completely. There is a certain interaction between the curing stages: on increasing JEF content, Stage 2 shifts to higher temperatures, because of the dilution of DDS in the formulation and the negative effect of the polyether structure of JEF on the amine-epoxy nucleophilic addition, which can results in the formation of non-reactive amine-ether complexes, as reported by Swier et al. [33]. On the contrary, when the amount of JEF is reduced, Stage 1 tends to shift to lower temperatures. This effect can be rationalized in terms of the decreasing negative impact of polyether structures on epoxy-amine reactivity, in spite of the dilution of amine groups of JEF.

As mentioned in Section 2.2, for sample preparation and characterization, the first curing stage was carried out at $90^{\circ} \mathrm{C}$ for $180 \mathrm{~min}$ and the second at $180^{\circ} \mathrm{C}$ for $180 \mathrm{~min}$. Fig. 3 shows the dynamic DSC postcurings after isothermal curing for different durations and temperatures for TGAPJEFDDS1_0.5_0.5 formulation. The residual peak associated to Stage 1, decreases until the cure is complete after $180 \mathrm{~min}$ at $90^{\circ} \mathrm{C}$, whereas the residual peak associated to Stage 2 remains constant, indicating that at $90^{\circ} \mathrm{C}$, DDS is not able to react. Moreover, the Stage 2 curing is completed after $180 \mathrm{~min}$ at $180^{\circ} \mathrm{C}$. These results confirm once more that this schedule allows a sequential and full curing. Fig. 3 also shows the increasing of $T_{g}$ on increasing the curing time during Stage 2 .

Table 2 shows equivalent results for all formulations. As can be seen, the residual heat associated to Stage $2\left(\Delta h_{1 . r e s}\right)$ is proportional to the DDS content and that DDS only reacts during Stage 2 .

TGAPJEFDDS1_0.1_0.9 and TGAPDDS11 produce, after dual curing $\left(180 \mathrm{~min}\right.$ at $90^{\circ} \mathrm{C}+180 \mathrm{~min}$ at $\left.180^{\circ} \mathrm{C}\right)$, residual heats of 1.5 and $4.5 \mathrm{~kJ} / \mathrm{ee}$, respectively. Since the curing temperature is below the ultimate $T_{g}$, vitrification can take place. As a consequence, both formulations need postcuring at a higher temperature (e.g. $250^{\circ} \mathrm{C}$ ) to achieve full curing.

\subsection{Thermal properties of epoxy-amine materials}

Table 2 shows how some thermal parameters, $T_{g} s$ and $\Delta C_{p}^{\prime} s$, associated to the different stages, change between pure formulations as a function of composition. Unreacted materials have increasing $T_{g}$ and decreasing $\Delta C_{p}$ with increasing DDS content, due to its high rigidity. Intermediate materials have decreasing $T_{g}$ with increasing DDS content due to the plasticizing effect caused by the growing amount of unreacted epoxy groups from TGAP and DDS molecules. A significant increase in $T_{g}$ takes place during stage 2 due to the higher $T_{g}$ of TGAP-DDS network. For the same reason, fully cured materials have increasing $T_{g}$ and decreasing $\Delta C_{p}$ and $\lambda$ (quotient of segment mobilities) with increasing DDS content. This behavior can be related with the higher crosslinking density of TGAP-DDS network, and to the higher rigidity of aromatic rings coming from DDS that prevent free bond rotations and reduce the segmental mobility of the materials. According with Gibbs and DiMarzio [34], an increase in the density of the crosslinking gives rise to an increase in the stiffness of the chains and consequently in $T_{g}$. This stiffness involves lower configurational entropy that can cause a reduction of $\Delta C_{p}$. 
Fig. 4 compares the experimental intermediate and final $T_{g}$ of the different formulations studied in this work, with predictions made using Fox equation [30]. The agreement between experimental and predicted data is excellent, as for other dual-curing systems $[10,12,35]$. This result suggests that the materials prepared are fully cured and highly homogeneous, without any part of the formulation forming a separate phase. Probably the participation of TGAP in both curing stages along with the hydrogen bond interactions between NHs of JEF and DDS help avoid the tendency of JEF to become incompatible with TGAP, when DDS is added to the formulation. The stacking interactions between aromatic groups of DDS and TGAP also help to compatibilize both components.

Fig. 4 also highlights (a) the possibility of designing materials with a broad range of glass transition temperatures, from $-5^{\circ} \mathrm{C}$ to $63^{\circ} \mathrm{C}$ in the intermediate stage and from $63^{\circ} \mathrm{C}$ to $235^{\circ} \mathrm{C}$ at the final stage, just by controlling the Stage $1 /$ Stage 2 ratio in the formulation, (b) the possibility of obtaining ungelled or gelled materials after the first curing stage and (c) the drastic change in properties that takes place between the intermediate and final materials, especially at higher DDS content. The wide property range of this family of materials makes them optimal for a variety of applications such as adhesives, structural composites or shape memory materials.

\subsection{Gelation of mixtures}

Gelation during curing was studied by isothermal DSC/TMA combined experiments and the results are summarized in Table 3. Most formulations gel during the first curing stage, with the exception of TGAPDDS11 and TGAPJEFDDS_0.1_0.9. The first one, as mentioned previously, does not react at $90^{\circ} \mathrm{C}$ and the second one does not contain enough JEF to reach gelation.

Assuming ideal stepwise behavior, the theoretical conversion of epoxy groups at the gel point, $\alpha_{\text {gel }}^{\text {theor }}$, was calculated using the well-known Flory-Stockmayer equation [25], considering that JEF and DDS only react during Stage 1 and 2, respectively. Formulations produce a valid gel point conversion only for values of $r$ (epoxy/hydrogen amine ratio) lower than $r_{c}$, where $r_{c}$ is the critical gelation ratio [25], calculated as

$r_{c}=(\mathrm{f}-1)(\mathrm{g}-1)$

For our system, with $f=3$ and $g=4$, we estimate a $r_{c}$ of 6 , that corresponds to a formulation TGAPJEFDDS_0.17_0.83. The experimental results agree with the theoretical $r_{c}$ value. The TGAPJEFDDS_0.1_0.9 formulation with a $r$ higher than $r_{c}=6$ does not reach gelation during Stage 1. In accordance with theoretical values, a formulation must contain 17 NH eq of JEF per 100 epoxy equivalents to be able to gel during stage 1, while TGAPJEFDDS_0.1_0.9 only has $10 \mathrm{NH}$ eq of JEF per 100 epoxy equivalents. Therefore, the theoretical value of $r_{c}$ is a useful tool to predict which formulations gel during stage 1 or 2 and the potential application of the different formulations. According to this value, it is expected that solid samples from TGAPJEF11 to TGAPJEFDDS1_0.17_0.83 can be shaped as conformable solids, whereas liquid samples from TGAPJEFDDS1_0.17_0.83 to TGAPDDS11 can show adhesive behavior.

Table 3 shows that the conversion at gel point, $\alpha_{\text {gel }}$, is strongly affected by the composition of the formulation, as predicted by the Flory-Stockmayer equation, decreasing with increasing DDS content. This result is in agreement with the fact that DDS is not able to react during the first stage of curing, since otherwise all formulations would be gelled at a theoretical conversion close to 0.408 , such as neat formulations. In the formulations that gel in Stage 1, it is observed that gel time first decreases with increasing DDS content but then increases again. This result is a trade-off between two effects, the decrease of gel conversion that tends to shorten the gel time and the dilution effect of DDS that tends to increase it.

Table 3 also shows that the theoretical conversion at gel point, $\alpha_{\text {gel }}^{\text {theor }}$, and the experimental values, $\alpha_{\text {gel }}^{\text {exp }}$, show similar trends, the experimental values being always higher. Setting aside experimental uncertainties associated with comparison of data using different analysis equipments, intramolecular loop formation observed in equivalents system [36,37], can explain this result, since this kind of reactions leads to cyclic structures and delays the gel point. Following the above line of reasoning, JEF-rich formulations should show higher differences between $\alpha_{\text {gel }}^{\text {theor }}$ and $\alpha_{\text {gel }}^{\text {exp }}$, as it is observed in Table 3, since the long and flexible structure of JEF allows more intramolecular cyclizations than the short and rigid structure of DDS. In the case of gelation with DDS, deviations from non-ideal behaviour should also be attributed to substitution effects, but the effect would be minor [25].

\subsection{Storage stability}

Characterization of the storage stability of intermediate materials is pivotal for applications where materials are required to be stored for prolonged periods before carrying out Stage 2 curing. In addition, certain latency is necessary when intermediate materials are manipulated. We studied experimentally the storage stability of all intermediate materials. DSC pans containing samples were cured $180 \mathrm{~min}$ at $90^{\circ} \mathrm{C}$ (after Stage 1) and then placed in sealed glass tubes which were inserted into thermostatic oil baths at $30^{\circ} \mathrm{C}$ for a maximum of 70 days. $T_{g} \mathrm{~s}$ and residual heats were measured after several storage durations. The results of the analysis are shown in Fig. 5.

The low reactivity of DDS at $30^{\circ} \mathrm{C}$ should ensure a certain storage stability but, additionally, vitrification, resulting in a significant mobility of reactive species, plays a prominent role. Initially, formulation TGAPJEFDDS_0.75_0.25 is already vitrified after Stage 1 ( $T_{g}$ higher than storage temperature, $30^{\circ} \mathrm{C}$ ), therefore it experiences very little changes with the passing of time. As the DDS content increases, the initial $T_{g}$ of the intermediate material decreases and the amount of available reactive species increase, hence 
allowing some slow reaction (i.e. increase in $T_{g}$ and decrease of residual heat) in the first weeks but, as the $T_{g}$ gets closer to or increases above storage temperature, vitrification reduces drastically the reaction rate, therefore imparting a significant storage stability afterwards. Changes during storage are more relevant for DDS-rich formulations, especially for TGAPJEFDDS1_0.1_0.9. However, from a practical point of view, such changes may not be relevant if the intermediate samples are processed within a few days, up to 2-3 weeks, so that handling or relevant properties (i.e. rheological behaviour) are only little affected. In any case, storage stability can be enhanced by storage in a fridge, at a lower temperature. This behaviour contrasts with that previously reported for dual-curing off-stoichiometric epoxy-amine formulations [10], where the use of a thermally latent catalyst for the epoxy homopolymerization taking place in the second curing stage ensured an excellent storage stability regardless of whether the material was vitrified or not.

\subsection{Dynamic mechanical properties of epoxy-amine thermosets}

Fig. 6 shows the $\tan \delta$ and storage moduli against temperature of final materials determined by DMA. The relaxation curves are shifted towards higher temperatures with increasing DDS content, in agreement with calorimetric $T_{g}$ 's shown in Table 2, This can be interpreted in terms of the increasing crosslinking density and, especially, the stiffness of polymer chains in DDS-rich formulations, imparted by the highly rigid aromatic structure of DDS. Although it is somewhat difficult to observe due to the overlapping with the beginning of thermal degradation, rubbery modulus increases with increasing DDS content, again due to the increase of crosslinking density and low chain mobility. Theoretical concentration of crosslinking points were estimated as 3.6 and $4.4 \mathrm{~mol} / \mathrm{kg}$ for TGAPJEF11 and TGAPDDS11, respectively, assuming that all epoxy groups have reacted. These values agree with the trend observed with the rubbery modulus. All DMA curves show unimodal peaks with no shoulders, indicating that the materials are highly homogeneous. The participation of TGAP in both curing stages ensures the covalent linkage between the TGAP-JEF and TGAP-DDS networks and a higher homogeneity of the material. Only TGAPJEFDDS_0.75_0.25 formulation presents a small shoulder at high temperature, which decreases with increasing DDS content. This suggests that there is a certain incompatibility between TGAP-JEF and TGAP-DDS networks, caused by the drastic change in molecular structure which gave rise to inter-molecular interactions between JEF and DDS. However, this produces only a broadening of the relaxation process, indicating some heterogeneity in the network structure, because both polymer networks are covalently linked.

Inset of Fig. 6 shows the tan $\delta$ curve of intermediate materials that gelled during stage 1 and have sufficient network build-up to withstand the strain without flowing. Intermediate TGAPJEFDDS_0.75_0.25 and TGAPJEFDDS_0.5_0.5 show higher damping capacity than fully cured samples due to the presence of unreacted TGAP and DDS, swelling and plasticizing the TGAP-JEF network. During Stage 2, $\alpha$-relaxations change from high and narrow to low and wide as commonly observed for highly crosslinked thermosets [25].

As it will be shown later, the temperature ranges where $\tan \delta$ peaks appeared along with their shape suggest that gelled intermediate materials are highly shape-conformable at near-ambient temperature, since at this temperature the materials are partially relaxed.

\subsection{Thermal stability of epoxy-amine thermosets}

Fig. 7 shows the thermogravimetric curves for all formulations studied. It can be observed that the degradative curves are shifted towards higher temperatures with increasing DDS content, due to the high stability provided by the aromatic rings of DDS and to the high crosslinking density of DDS-rich formulations. It can also be observed that the degradation takes place in two steps. Observing the thermograms of the neat TGAPJEF1 $\left(300-420^{\circ} \mathrm{C}\right)$ and TGAPDDS1 $\left(350-500^{\circ} \mathrm{C}\right)$ networks, the degradation steps of the dual formulations can be mapped (Fig. 7b). However, it should be pointed out that the degradation steps overlap significantly and therefore it is not possible to assign each peak exclusively to each neat network, in contrast with other dual-curing systems [6,10]. Moreover TGAPJEF11 degrades in two overlapped steps. The rings formed by intramolecular cyclization, more stable than the rest of network, might be tentatively considered responsible for the appearance of a peak at higher temperatures. The presence of aromatic rings coming from DDS leads to a higher char yield in the thermosets with a higher proportion of this amine.

\subsection{Mechanical characterization}

Microindentation hardness measurements are very useful to study the resistance of one body against penetration to another under static loads. These measurements were carried out with a Knoop microindenter and the results are shown for all the materials prepared in Fig. 8(a). As can be seen, on increasing the proportion JEF in the thermosets, microhardness decreases, due to the flexibility introduced by the long chains of JEF.

The results of the impact tests are collected in Fig. 8(b) for all the materials prepared. The values correspond to the energy consumption of the material preventing crack propagation. It is possible to observe that the modification of neat TGAPDDS11 with JEF improves impact strength, doubling the value for the neat TGAPJEF11 formulation. Toughness enhancement is achieved because stresses acting on the TGAPDDS matrix can be efficiently transferred to the softer TGAPJEF matrix across the covalent bonding between TGAP and both types of networks.

Epoxy systems with low hardness and high impact resistance can be suitable for a range of applications where surfaces require a flexible coating or where fibre reinforced composite parts are required which always remain flexible such as frequent impact areas, 
connecting tubes for ducting or articulated components. When necessary, by replacing the JEF $\left(M_{w}=400 \mathrm{~g} / \mathrm{mol}\right)$ used in this work with more flexible JEF (e.g. $M_{w}=4000 \mathrm{~g} / \mathrm{mol}$ ) the range of properties can be extended, reducing the inherent rigidity of epoxy systems. For applications requiring materials with enhanced toughness and flexibility but having a high $T_{g}$, TGAPJEFDDS_0.25_0.75 could be attractive.

\subsection{Prospective applications of the developed materials}

In this last section, potential applications of the prepared materials are explored and discussed. First of all, the intermediate ungelled materials were tested for adhesive bonding (see Fig. 9). First, the uncured TGAPJEFDDS_0.1_0.9 formulation was poured into a vial and cured at $90^{\circ} \mathrm{C}$ for $180 \mathrm{~min}$, then a small amount of this liquid formulation was applied on top of the metal rod (with $800 \mathrm{~g}$ of weight) and a screw was placed on the adhesive applied patch. The assembly was put in the oven for the second curing stage $\left(180^{\circ} \mathrm{C}\right.$ for $180 \mathrm{~min}$ plus $250^{\circ} \mathrm{C}$ for $30 \mathrm{~min}$ ). At the end of curing, excellent adhesion was achieved, as the two pieces had adhered to each other perfectly and they could not be separated by any hand manipulation. It was estimated that the screw receives an axial tension of $280 \mathrm{MPa}$ in the configuration showed (see Fig. 9). Although, the curing schedule followed in this section is the same as that employed in the rest of the work, curing durations and temperatures can be optimized to reduce energy consumption. In accordance with the $T_{g} \mathrm{~S}$ of the intermediate $\left(-5^{\circ} \mathrm{C}\right)$ and final $\left(195^{\circ} \mathrm{C}\right)$ materials and the kinetic parameters available, first curing stage may be performed at room temperature for $24 \mathrm{~h}$ (preparation of the adhesive) and second curing stage for $60 \mathrm{~min}$ at $200^{\circ} \mathrm{C}$.

Secondly, we investigated the conformability of the gelled intermediate materials and the shape memory potential of final materials. TGAPJEFDDS_0.75_0.25 formulation was chosen and representative samples were prepared. Having and intermediate $T_{g}$ of $36^{\circ} \mathrm{C}$, it can be readily shaped. Fig. 10 illustrates the procedure employed. (a) The liquid formulation was poured into a steel mould and cured at $90^{\circ} \mathrm{C}$ for $180 \mathrm{~min}$ to obtain an intermediate prismatic-shaped material. (b) The deformable intermediate material at $40{ }^{\circ} \mathrm{C}$ was easily rolled onto a glass vial of $24 \mathrm{~mm}$ of diameter covered with a layer of Teflon to obtain the bent-shaped surface. (c) To fix permanent shapes, the sample was heated up at $180^{\circ} \mathrm{C}$ for $180 \mathrm{~min}$ (Stage 2), cooled down to room temperature and peeled off from the moulds. (d) The programming of the temporary shape (prismatic-shape) was performed between two stainless steel plates at programming temperature of $90^{\circ} \mathrm{C}$ applying sufficient pressure to flatten the sample and then cooling down to room temperature. (e) The recovery of the original permanent bent-shape was made by immersing the sample into a silicon bath at $90^{\circ} \mathrm{C}$. Full shape recovery was achieved in approximately $30 \mathrm{~s}$. This time can be shortened by increasing the temperature of the silicon bath. Although no formal quantification of the shape memory capability was done, the shape recovery was virtually reproducible in at least 4 subsequent cycles of shape programming. These promising results can be exploited in the field of the shape memory polymers in applications such as actuators, self-deployable structures or sensors.

One of the attractive features of this new family of materials, compared to existing systems, is that they are prepared with commercial materials at affordable prices and formulations are free of solvents and catalysts [10,38]. Replacing petrochemical-derived epoxy monomers with those obtained from natural resources, such as tetraepoxy derivative of bis-eugenol [39], or other vegetable oil based epoxides [40] completely environmentally-friendly materials can be obtained.

\section{Conclusions}

A new family of dual-curable epoxy thermosets was designed, prepared and characterized. The curing involves two consecutive amine-epoxy polycondensation at different temperatures each involving a diamine with a different nucleophilic character, and therefore, reactivity.

Intermediate materials have a remarkable stability at room temperature for at least two months, depending on the formulation composition. This stability is controlled by the low reactivity of the aromatic amine used as curing agent of stage 2 and, especially, by vitrification taking place in some formulations during the first curing stage or during storage.

The novel strategy is versatile and allows tuning of intermediate and final material properties through an adequate selection of monomers and by changing the relative contribution of the two curing steps. Prepared materials show characteristics ranging from ungelled liquids to highly crosslinked solids, whose applications range from adhesives to conformable smart materials with shape memory. The toughness of brittle epoxy thermosets can be easily enhanced by partial replacement of the aromatic rigid amine by a flexible aliphatic amine of higher molecular weight.

Some outstanding features of the proposed strategy are the possibility to use low-cost commercial products, solvent-free reaction conditions, no requirement of initiators or additives, and highly homogeneous materials thanks to the participation of the epoxy monomer in both stages of curing via two consecutive step-growth polymerizations.

\section{Acknowledgments}

This work was supported by the MCIU (Ministerio de Ciencia, Innovación y Universidades) and FEDER (Fondo Europeo de Desarrollo Regional) [MAT2017-82849-C2-1-R and MAT2017-82849-C2-2-R]; Generalitat de Catalunya [2017-SGR-77 and Serra Húnter program]. 


\section{Appendix A. Supplementary material}

Supplementary data to this article can be found online at https://doi.org/10.1016/j.eurpolymj.2019.04.018.

\section{References}

[1] X. Ramis, X. Fernández-Francos, S. De La Flor, F. Ferrando, À. Serra, Click-based dual-curing thermosets and their applications, in: Q. Guo (Ed.), Thermosets second ed. Structure, Properties and Application, Ch.16, pp. 511-541, Elsevier, 2018. 10.1016/B978-0-08-101021-1.00016-2.

[2] D.P. Nair, N.B. Cramer, J.C. Gaipa, M.K. McBride, E.M. Matherly, R.R. McLeod, R. Shandas, C.N. Bowman, Two-stage reactive polymer network forming systems, Adv. Funct. Mater. 22 (2012) 1502-1510, https://doi.org/10.1002/adfm.201102742.

[3] M. Romero, X. Fernández-Francos, X. Ramis, Sequential heat release: an innovative approach for the control of curing profiles during composite processing based on dual-curing systems, Polym. Int., 2018. 10.1002/pi.5743.

[4] D. Santín, O. Konuray, X. Fernàndez-Francos, X. Ramis, Kinetics analysis and simulation of sequential dual-curing systems with independent thermal activation, Thermochim. Acta 673 (2019) 158-168, https://doi.org/10.1016/j.tca.2019.01.023.

[5] H. Matsushima, J. Shin, C.N. Bowman, C.E. Hoyle, Thiol-isocyanate-acrylate ternary networks by selective thiol-click chemistry, J. Polym. Sci. Part A Polym. Chem. 48 (2010) 3255-3264, https://doi.org/10.1002/pola.24102.

[6] G. Gonzalez, X. Fernandez-Francos, A. Serra, M. Sangermano, X. Ramis, Environmentally-friendly processing of thermosets by two-stage sequential aza-Michael addition and free-radical polymerization of amine-acrylate mixtures, Polym. Chem. 6 (2015) 6987-6997, https://doi.org/10.1039/c5py00906e.

[7] A.O. Konuray, A. Ruiz, J.M. Morancho, J.M. Salla, X. Fernández-Francos, À. Serra, X. Ramis, Sequential dual curing by selective Michael addition and free radical polymerization of acetoacetate-acrylate-methacrylate mixtures, Eur. Polym. J. 98 (2018) 39-46, https://doi.org/10.1016/j.eurpolymj.2017.11.003.

[8] W. Xi, H. Peng, A. Aguirre-Soto, C.J. Kloxin, J.W. Stansbury, C.N. Bowman, Spatial and temporal control of thiol-Michael addition via photocaged superbase in photopatterning and two-stage polymer networks formation, Macromolecules 47 (2014) 6159-6165, https://doi.org/10.1021/ma501366f.

[9] N. Moszner, V. Rheinberger, Reaction behaviour of monomeric $\beta$-ketoesters, 4. Polymer network formation by Michael reaction of multifunctional acetoacetates with multifunctional acrylates, Macromol. Rapid Commun. 16 (1995) 135-138, https://doi.org/10.1002/marc.1995.030160207.

[10] O. Konuray, N. Areny, J.M. Morancho, X. Fernández-Francos, A. Serra, X. Ramis, Preparation and characterization of dual-curable off-stoichiometric amine-epoxy thermosets with latent reactivity, Polymer 146 (2018) 42-52, https://doi.org/10.1016/j.polymer.2018.05.040.

[11] O. Konuray, X. Ramis, X. Fernández-Francos, À. Serra, State of the art in dual-curing acrylate systems, Polymers 10 (178) (2018) 1-24, https://doi.org/10. 3390/polym10020178.

[12] X. Fernández-Francos, A.-O. Konuray, A. Belmonte, S. De la Flor, À. Serra, X. Ramis, Sequential curing of off-stoichiometric thiol-epoxy thermosets with a custom-tailored structure, Polym. Chem. 7 (2016) 2280-2290, https://doi.org/10.1039/C6PY00099A.

[13] J.A. Carioscia, J.W. Stansbury, C.N. Bowman, Polymer 48 (2007) 1526-1532, https://doi.org/10.1016/j.polymer.2007.01.044.

[14] H. Peng, D.P. Nair, B.A. Kowalski, W. Xi, T. Gong, C. Wang, M. Cole, N.B. Cramer, X. Xie, R.R. McLeod, C.N. Bowman, High performance graded rainbow holograms via two-stage sequential orthogonal thiol-click chemistry, Macromolecules 47 (2014) 2306-2315, https://doi.org/10.1021/ma500167x.

[15] Y. Jian, Y. He, Y. Sun, H. Yang, W. Yang, J. Nie, Thiol-epoxy/thiol-acrylate hybrid materials synthesized by photopolymerization, J. Mater. Chem. C. 1 (2013) 4481-4489, https://doi.org/10.1039/c3tc30360h.

[16] F. Gamardella, V. Sabatini, X. Ramis, À. Serra, Taylor-made thermosets obtained by sequential dual-curing combining isocyanate-thiol and epoxy-thiol click reactions, Polymer (2019), submitted for publication.

[17] D. Perrot, C. Croutxé-Barghorn, X. Allonas, UV-curable thio-ether-urethane network with tunable properties, J. Polym. Sci. Part A: Polym. Chem. 54 (2016) 3119-3126, https://doi.org/10.1002/pola.28196.

[18] A. Rybak, L. Jarosinski, K. Gaska, C. Kapusta, Graphene nanoplatelet-silica hybrid epoxy composites as electrical insulation with enhanced thermal conductivity, Polym. Compos. 39 (2018) E1682-E1691, https://doi.org/10.1002/pc.24666.

[19] A. Rybak, J. Nieroda, Aluminosilicate-epoxy resin composite as novel material for electrical insulation with enhanced mechanical properties and improved thermal conductivity, Polym. Compos., 2018. 10.1002/pc.25167 (in press).

[20] C.A. May (Ed.), Epoxy resins: Chemistry and Technology, second ed., Marcel Dekker, New York, 1988 , Chapter 1.

[21] E.M. Petrie, Epoxy Adhesive Formulations, McGraw-Hill, New York, 2006.

[22] G. Zhou, W. Wang, M. Peng, Molecular-level dispersion of rigid-rod sulfonated aromatic polyamides in epoxy resin for extraordinary improvement in both strength and toughness, Polymer 163 (2019) 20-28, https://doi.org/10.1016/j.polymer.2018.12.048.

[23] Norme Française Enregistré. Composés d'époxydes, determination de l'equivalent époxyde, NF T 51-522, AFNOR, September 1975.

[24] C. Acebo, M. Alorda, F. Ferrando, X. Fernández-Francos, A. Serra, J.M. Morancho, J.M. Salla, X. Ramis, Epoxy/anhydride thermosets modified with end-capped star polymers with poly(ethyleneimine) cores of different molecular weight and poly(e-caprolactone) arms, Exp. Polym. Lett. 9 (2015) 809-823, https://doi. org/10.3144/expresspolymlett.2015.76.

[25] J.P. Pascault, H. Sautereau, J. Verdu, R.J.J. Williams, Thermosetting Polymers, Marcel Dekker, New York, 2002.

[26] J.P. Pascault, R.J.J. Williams, Overview of thermosets: Present and future, in: Q. Guo (Ed.), Thermosets, Structure, Properties and Application, second ed., pp. 3-34, Elsevier, 2018. 10.1016/B978-0-08-101021-1.00001-0 (Ch.11).

[27] G.P.J.M. Tiemersma-Thoone, B.J.R. Scholtens, K. Dušek, M. Gordon, Theories for network formation in multistage processes, J. Polym. Sci. Part B: Polym. Phys. 29 (1991) 463-482, https://doi.org/10.1002/polb.1991.090290409.

[28] R.J.J. Williams, C.C. Riccardi, K. Dušek, Build-up of polymer networks by initiated polyreactions, Polym. Bull. 25 (1991) $231-2377$.

[29] K. Dušek, M. Dušková-Smrčková, Polymer networks from precursors of defined architecture. Activation of preexisting branch points, Macromolecules 36 (2003) 2915-2925, https://doi.org/10.1021/ma021666b.

[30] T.G. Fox, Influence of diluent and of copolymer composition on the glass temperature of a polymer system, Bull. Am. Phys. Soc. 1 (1956) 123.

[31] J.M. Hutchinson, F. Shiravand, Y. Calventus, I. Fraga, Isothermal and non-isothermal cure of a tri-functional epoxy resin (TGAP): a stochastic TMDSC study, Thermochim. Acta 529 (2012) 14-21, https://doi.org/10.1016/j.tca.2011.11.008.

[32] R.J. Varley, J.H. Hodgkin, D.G. Hawthorne, G.P. Simon, Toughening of a trifunctional epoxy system. II. Thermal characterization of epoxy/amine cure, J. Appl. Polym. Sci. 60 (1996) 2251-2263, https://doi.org/10.1002/(SICI)1097-4628(19960620)60:12<2251::AID-APP24>3.0.CO;2-8.

[33] S. Swier, G. Van Assche, W. Vuchelen, B. Van Mele, Role of complex formation in the polymerization kinetics of modified epoxy-amine systems, Macromolecules 38 (2005) 2281-2288, https://doi.org/10.1021/ma047796x.

[34] J.H. Gibbs, E.A. DiMarzio, Nature of the glass transition and the glassy state, J. Chem. Phys. 28 (1958) 373, https://doi.org/10.1063/1.1744141.

[35] A. Belmonte, X. Fernández-Francos, À. Serra, S. De la Flor, Phenomenological characterization of sequential dual-curing of off-stoichiometric "thiol-epoxy" systems: towards applicability, Mat. Des 113 (2017) 116-127, https://doi.org/10.1016/j.matdes.2016.10.009.

[36] Y. Tanaka, J.L. Stanford, R. Stepto, Interpretation of gel points of an epoxyamine system including ring formation and unequal reactivity: measurements of gel points and analyses on ring structures, Macromolecules 45 (2012) 7197-7205, https://doi.org/10.1021/ma300984u.

[37] L. Matejka, Amine cured epoxide networks: formation, structure, and properties, Macromolecules 33 (2000) 3611-3619, https://doi.org/10.1021/ma991831w.

[38] F. Pilate, A. Toncheva, P. Dubois, J.-M. Raquez, Shape-memory polymers for multiple applications in the materials world, Eur. Polym. J. 80 (2016) 268-294, https://doi.org/10.1016/j.eurpolymj.2016.05.004.

[39] D. Guzmán, A. Serra, X. Ramis, X. Fernández-Francos, S. De la Flor, Fully renewable thermosets based on bis-eugenol prepared by thiol-click chemistry, React. Funct. Polym. 136 (2019) 153-166, https://doi.org/10.1016/j.reactfunctpolym.2018.12.024. 
[40] A. Llevot, Sustainable synthetic approaches for the preparation of plant oil-based thermosets, J. Am. Oil Chem. Soc. 94 (2017) 169-186, https://doi-org.recursos.biblioteca.upc.edu/10.1007/s11746-016-2932-4. 